\title{
Word Formation of Photography Terminologies
}

\author{
Akhmad Multazim \& Ermayni Sari Nurdin \\ jaymultazim@gmail.com \& esnurdin@gmail.com \\ Department of English Education, Universitas Ahmad Dahlan
}

\begin{abstract}
Technology and social media affected the use of word as part of language in certain domain as a means of communication. The research objectives were to find out the types of word formation, the dominant type and the reason of dominancy of word formation of photography terminologies in online magazine outdoorphotographer.com. It was a descriptive qualitative research concerning on exploring language particularly on word level. Data were collected from articles published on online magazine from January to August 2018 by reading, note-taking and check-listing. To analyze the types of word formation, a theory by Stockwell and Minkova was used and to analyze the meaning of the terminologies, Cambridge and Oxford dictionaries were used. The result showed that there were 198 photography terminologies found. These terminologies were classified into six types of word formation, namely acronym (12 data), borrowing (3 data), compounding (166 data), clipping (3 data), derivation (3 data) and eponym (1 datum). The most dominant type was compounding. It was very dominant due to its simplicity to form a new word by simply combining two or more words without any change of its elements. This research revealed many photography terminologies that could be used to enrich vocabulary
\end{abstract}

Keywords: Word formation, Photography terminologies, Outdoorphotographer.com

\section{Introduction}

Language is always interesting to discuss, whether it is written or spoken form. There are languages in the world and English is one of them. Language, including English, is shaped by form of words in arranging the representation of the message from a larger unit to a smaller unit. The larger unit can be in the level of sentences to discourses, while the smaller can be in the level of phrases to words. According to John (2018), sentence is at the top part of the hierarchy, so it is the largest unit which we will be considering (though some grammars look beyond the sentence). At the end of the hierarchy, word is at the lowest level eventhough some grammars go below the word to consider morphology, the study of how word is constructed.
The emergences of technological inovation influence linguistic occurrence in making new terminologies as needed in the way of forming words. This matter gets in touch to morphology because the analysis deals with word-structure. According to Arronof \& Fudeman (2011, p. 1), morphology refers to mental system in linguistics branch dealing with word, its internal structure, and how it is formed. The main concern deals with formation process in language that can be analysed in scope of word analysis. An approach to this is usually said as wordformation which relates to process in forming word with various ways depending on its use.

It is interesting to explore the current terminologies of photography in word formation process especially in outdoorphotographer.com which is according to constantly.com, the web is one of the great 
photography websites providing information about photography. The first reason is young people follow a trend of posting pictures on social media like Facebook, WhatsApp, Instagram, and many other social media because social media is rapidly developed in influencing social behavior of sharing picture (Kofoed, Jette and Larsen M.C, 2016). Then, the other reason of choosing the topic is that because of the development of technology that increases rapidly including photography, motivate people's desire to know about how it works properly as beneficial profession to deal with. Thus, to fulfill the needs of photographing, they need to know and learn all about photography at least by knowing the terminology itself. In short, this study deals with photography terminology in which it develops greatly recently since the era of social media increases rapidly. This study analyzes the types word formation of photography terminology and which one is dominant.

Photography is also possible to be a means of communication to deliver messages. Photography functions as a communication medium, setting the composition well. It will make it easy for an observer or connoisseur of art photography to capture what the photographer wants to convey through his work. Someone is possible to see news by capturing its contents without reading it, or just as curious trigger tool. In this case photo works can also be said as medium that has the use (functional) value and at the same time as an instrument because it is used as a tool in the communication process of delivering messages or ideas from the creator of the photo (Soedjono, 2007).

\section{Morphology}

Word formation is the main topic of morphology in which morphology is the study of forming word. Lieber (2009) states that the study of morphology is about to reveal how to form word and the ways of those words are shaped in different types. A word can be form with a single morpheme or combination of morphemes. Morpheme is the smallest part of a word which is no longer meaningful if it is divided. O'Grady and Guzman (2001) state that morpheme is the smallest language unit that brings information about function and meaning. Basically, there are two types of morpheme, namely free morpheme and bound morpheme. A morpheme which can be a word by itself is called free (O'grady and Guzman, 2001). Katamba (2006) states that bound morpheme that only can occur if it is attached to or tied to another morpheme (free morpheme) in occurrence of root, stem or base is called as affix. Affixes will be meaningless if it is not tied to free morpheme.

Katamba (2006) classifies affixes into three classifications based on their positions toward free morpheme as follow:

1) Prefix: an affix that is attached before a root, base, or a stem, such as $\{$ re- $\},\{$ un- $\}$, and $\{$ in- $\}$. e.g. un-kind, re-make, inaccurate.

2) Suffix: an affix that is attached after a root, base, or a stem, such as $\{-\mathrm{ly}\},\{-\mathrm{er}\},\{-\mathrm{ed}\}$. e.g. kind-ly, play-er, walk-ed.

3) Infix: an affix that is inserted inside a root, but infixing is not common in English.

\section{Word Formation}

According to Stockwell and Minkova (2001), English word-formation process is divided into ten types. They are Neologisms (creation de novo), Blending, Acronym (Initialization \& Reverse), Clipping, Derivation (Affixation \& Conversion), Eponyms, Echoic, Reduplication Borrowing, and Compounding.

\section{a. Neologism or Coinage}

Neologism is a word formation in which a word is coined based on its use in particular. This kind of word formation is created and used in manufacture and commercial field to specifically name a product such as Kodak (the name of Camera) created by George Eastman, and Honda (a kind of vehicle), Teflon (a kind of kitchen ware).

\section{b. Blending}

Blending is a kind of word formation that combines two or more existing words to construct or form a new word. Stockwell \& Minkova (2001) state that in blending, parts of two or more existing words are yoked together usually first part of one word and the 
last part of the second to make a word that combines the meaning of the two words, for example: urinalysis (urine and analysis), Edutainment (education and entertainment) and Brunch (Breakfast and Lunch).

\section{c. Acronym}

1) Initialisms

According to Stockwell \& Minkova (2001), if the letters that form the acronym are pronounced individually like HTTP (Hypertext Transfer Protocol), such acronym is called initialism. The other examples of initialisms are LCD (Liquid Crystal Display), WHO (World Health Organization), and WTO (World Trade Organization). It is clear that in initialisms, each letter is pronounced independently one by one.

\section{2) Reverse Acronyms}

Stockwell \& Minkova (2001) state that in reverse acronyms, the creator starts with a word they want as their name such as CORE (Congress of Racial Equality), NASA (National Aeronautics and Space Administration) in which the letters of CORE or NASA are not pronounced independently but they are pronounced like common words.

\section{d. Creation by Shortening (Clipping)}

Shortening is deleting some parts of a word to make it shorter. Stockwell \& Minkova (2001) explain that shortening can take any part of a word, usually one syllable and omit the rest, like ad (advertisement), phone (telephone), flu (influenza), plane (airplane). O'Grady and Guzman (2001) state clipping is a kind of word formation that a deletion of some syllables in polysyllabic word happens to make it shorter. The other examples of Clipping are quiz (inquisitive), prof (Professor), etc.

\section{e. Derivation}

\section{1) Derivation by Affixation}

Stockwell \& Minkova (2001) state that derivation consists in making up new words by adding endings to more basic forms of the words. O'Grady and Guzman (2001) define that derivation is a process of forming word by adding affixes into its base in producing a new word. Therefore, the lexical meaning and function change. Example: Reader = read is added with $\{-\mathrm{er}\}$. Read is a verb then it gets $\{-$ er\} that changes the class or word from verb into noun (the agent who does the action)

2) Derivation without Affixation

Derivation is creating a new word from already existing word without changing the form. Derivation without affixation is also called as conversion (Stockwell \& Minkova, 2001). Stockwell and Minkova (2001) add that noun, adjective, adverb and verb look alike and sound alike. For examples are as follow:

\section{I sent you a text last night. Text me if you need me!}

The word text in first sentence stands as a noun. On the other hand, the word text in the second sentence stands as a verb. It is clear that there is no change of the form of the word, but there is a change of the word category from a noun into a verb.

\section{f. Eponym}

Eponym is a creation of words based on names (Stockwell \& Minkova, 2001). They add that eponyms are associated with the real people, imaginary creatures or mythological figures, and places.

1) Based on personal name or real people

Eponym based on real people or personal name is a creation of word based on the name of a real person who invented something. For example, $\mathrm{Ohm}$ (unit of electrical resistance) is created based on its inventor George Simon Ohm (German physicist).

2) Based on geographical name or place

Eponym based on place or geographical name is a creation of word based on the name of the place where the thing is invented. For example, cheddar (a village in Somerset) is created based on the name of place where the cheese first came.

3) Based on imaginary creature (literature) and mythology

Eponym based on imaginary creature and mythology is a word creation that relates to 
creatures in literary works and mythology. For example: Atlas, the name of figure in Greek mythology that was punished by Zeus to support the earth on shoulder.

\section{g. Echoic or Onomatopoeia}

Echoic is a creation of word by imitating the sound that the word represents (Stockwell \& Minkova, 2001). This type of word formation is not really productive especially in English. For examples: bang, meow, moo, etc.

\section{h. Reduplication}

Stockwell \& Minkova (2001) state that reduplication is a word creation by repeating part or all parts of word. Sapir (1921) in Katamba (1994) states that reduplication is the repetition of the base of a word partially or in its entirety. For examples: fifty-fifty, brain drain, and dum dum.

\section{i. Borrowing}

Borrowing is a creation of word by adopting foreign words to be used in the language. Katamba (1994) explains that the collection of words (vocabulary) or a language can be increased by borrowing vocabulary from other languages. For example: Rambutan (a borrowing word from Indonesian) and Omellette (a borrowing word from French).

\section{j. Compounding}

Compounding is a creation of word by combining or mixing two words. Stockwell \& Minkova (2001) state that compounding is the largest word formation and the most important source of new words. O'Grady and Guzman (2001) state that compounding is a process of combining two or more separate lexical categories such as noun, adjective, adverb and preposition to produce a new word. For examples: nothing, green house, shoemaker, wallpaper, etc.

There are various types of compounding. According to Carstairs-McCarty (2002), there are five types of compound; Compound Noun,
Compound Verb, Compound Adjective, Phrasal Word and Neo-Classical Compound.

1) Compound Noun

Compound noun is combination of words in which the head of construction is a noun. The combination of compound noun can be in several patterns as follow:

a) Noun + Noun: exercise book, cloth hanger

b) Verb + Noun: playtime, washing machine

c) Adjective + Noun: smartphone, whiteboard

d) Preposition + Noun: outdoor, on time

2) Compound Verb

Compound verb is combination of words in which the head of construction is a verb. The combination of compound verb can be in several patterns as follow:

a) Verb + Verb: drink-drive, blow-dry

b) Noun + Verb: handwash, daydream

c) Adjective + Verb: clear cut, white wash

d) Prepositional: overcook, underexpose

3) Compound Adjective

Compound adjective is combination of words in which the head of construction is a adjective. The combination of compound adjective can be in several patterns as follow:

a) Noun + Adjective: ore-rich, home sick, heart broken

b) Adjective + Adjective : kind hearted, pure white

c) Preposition + Adjective: overactive, over confident

4) Phrasal Word

Another form of compound is Phrasal word. Carstairs-McCarty (2002) state that the item functions as word but its appearance of the structure is in form of phrase like mother in law.

5) Neo Classical Compound

Neo classical compound is word formation by combining affixes of Latin or Greek with other elements to form a new word. The affixes of Latin or Greek may occur either at the initial position or final position (Bauer, 1983). For examples are teleconference and hydrology. 


\section{Research Method}

This research employed descriptive qualitative method. The data were taken from online magazine outdoorphotographer.com. According to Creswell (2007), the source of data in qualitative research can be obtained through documents and archives, open-ended interviews, subject journaling, participant observation, and casual chatting. Thus, in applying for the research, the sources of data were articles in outdoorphotographer.com published from January to August 2018 and dictionaries as the source to analyze the meaning of photography terminologies. Check-list and note-taking were the instruments of this research. Data analysis covers three main points of analysis: the types of word formation process, the meaning by referring to dictionaries, and conclusion.

\section{Discussion}

\section{Types of Word Formation}

Out ot ten types of word formation, there are only six types of word formation of photography terminologies found. They are acronym, borrowing, compounding, creation by shortening (clipping), derivation and eponym.

\section{a. Acronym}

There are two types of Acronyms found in this study; initialism and reverse acronym.

\section{1) Initialism}

Initialism is an acronym in which the new word is constructed of the combination of the initial letters of each word and the new word formed is pronounced by pronouncing each letter independently. For examples:

\section{a) SLR}

Chances are your digital SLR will have something similar. (Flash: Slow-Speed Sync, February 26, 2018)

It can be seen that SLR is an acronym and it is photography terminology. Morphologically, SLR consists of three free morphemes based on the elements constructing the word. SLR is a noun that has three constituents or elements constructing this word. They are S (Single), L (Lens) and R (reflects). SLR belongs to initialism acronym because each letter constructing the new word represents one existing word and is pronounced one by one independently.

This new word consists of three letters representing three elements of it and has a new meaning representing the three constructing elements. S (Single) means only one, L (lens) means transparent material or a piece of glass with curved sides to concentrate or disperse light rays, used independently or singly (as in a magnifying glass) or with other lenses (like in a telescope) and R (Reflect) means throwing back without absorbing. In photography terminology, SLR is a kind of camera that uses single line lens system to pass the light to two places (focal plane and viewfinder) allowing the photographer to see the object directly through camera screen or viewfinder.

b) LCD

When you exhale, be sure to aim your breath away from the viewfinder, front lens element and LCD. Your breath will fog them up. (Year-Round Photo Thoughts, April 2, 2018)

It can be seen that $L C D$ is an acronym and it is photography terminology. Morphologically, $L C D$ consists of three free morphemes based on the elements constructing the word. $L C D$ is a noun which has three constituents or elements constructing this word. They are L (Liquid), C (Crystal) and D (Displayer). $L C D$ belongs to initialism acronym because each letter constructing the new word represents one existing word and is pronounced one by one independently.

The word LCD consisting three letters representing three words has a new meaning representing three words constructing it. L (Liquid) means a substance which flows freely but is of static volume, having a consistency like that of oil or water, C (Crystal) means Highly transparent glass with a high refractive index and D (Display) means Show (data or an image) on a computer, television, or other screen. In photography, 
LCD is the screen on a camera made of liquid crystal that modulates light to show the image of the object.

\section{c) $\mathrm{B} \& \mathrm{~W}$}

Along the options bar at the top of the Photoshop workspace, go to IMAGE $>$ ADJUSTMENTS $>B \& W$ (Color Be Gone, March 19, 2018)

It can be seen that $B \& W$ is an acronym and it is photography terminology. Morphologically, $B \& W$ consists of three free morphemes based on the elements constructing the word. $B \& W$ has three constituents or elements constructing this word. They are B (Black), \& (symbol of and) and $\mathrm{W}$ (White). $B \& W$ belongs to initialism acronym because each letter constructing the new word represents one existing word and is pronounced one by one independently.

The word $B \& W$ consists three letters representing three words and has a new meaning representing three words constructing it. B (Black) means the darkest color owing to the absence of or total absorption of light; the opposite color of white, \& (and) means conjunction to connect the words of some parts and W (White) means the color of fresh snow or milk, due to the reflection of all visible rays of light; the opposite color of black. In photography, B\&W is a kind of photography in which all kinds of color are removed except black and white.

\section{2) Reverse Acronym}

Reverse Acronym is an acronym in which a new word formed is pronounced dependently as common words not independently letter by letter. In this research, there is only one word categorized as reverse acronym, ISO.

Tripod: To get the best quality capture, you want to use as low an ISO as your camera has. (Photographic Portals January 22, 2018)

Morphologically, ISO consists of three free morphemes based on the elements constructing the word. It is an acronym of International Standardization Organization.
ISO is an international organization that standardizes the sensitivity ratings for camera sensors. In technical term of photography, ISO refers to the settings of dark and bright. The higher the level of ISO, the brighter the image will be.

\section{b. Borrowing}

Borrowing means adopting words from foreign language. In this research, there are three photography terminologies classified into borrowing words. They are angle, aperture, and portrait.

\section{1) Angle}

Will they be on the proper side of the road given the angle of the sun? (Backtrack for Success, January 29, 2018)

Angle is adopted from Latin Angulus which means corner. Morphologically, it consists of one free morpheme. In photography terminology, angle means the position or corner from where the image is viewed or captured.

\section{2) Aperture}

If necessary, raise your ISO or open your aperture to attain the necessary shutter to freeze the moment. (Create Captivating Creature Captures, February 12, 2018)

Aperture is adopted from Latin Apertura /apert which means open. Morphologically, it consists of one free morpheme. In photography terminology, aperture is the opening of the shutter in a lens that determines how much the light will get in to the sensor through the lens.

\section{3) Portrait}

You need to make a portrait in the bright sun, which dictates it will be contrast. (Flash: High-Speed Sync, February 19, 2018)

Portrait is adopted from French portraire which means portray or depict. Morphologically, it consists of one free morpheme. In photography, portrait is a kind of photography that focuses only on capturing the face or head and the shoulder or the object. 


\section{c. Compounding}

Compounding is a kind of word formation by combining or mixing two or more words to produce a single form of new word. In this study, compounding is the most dominant type of word formation. There are 166 data categorized as compounding. For examples are as follow:

\section{1) Action Photography}

One of my photo mantras is "Exhaust All Possibilities," and it should be applied to action photography. (Pan Like A Pro, March 26, 2018)

Action photography is classified into compounding. Morphologically, Action Photography consists of two free morphemes (action and photography). This terminology is constructed by two elements. The elements are noun + noun. Action stands as modifier that modifies the head and photography stands as the head. Action photography is noun compounding in which the head is a noun.

Action photography has a new meaning in which the meaning is constructed by its constituents. Action means a physical movement and photography is an activity or job of taking photograph or picture or filming. Action photography is a kind of photography that which captures or shoots person in action that requires physical ability like fighting and martial art.

\section{2) Backlight}

This image is all about the backlight. (Aim for The Sun, July 2, 2018)

Backlight is classified into compounding. Morphologically, it consists of two free morphemes (Back and Light). This terminology is constructed by two elements. They are back and light. The word back stands as a modifier and light stands as the head. Back is an adjective and light is a noun. This construction is noun compounding because the head of the elements is a noun.

Backlight as a terminology in photography conveys meaning which is constructed by its elements. Back means position directly behind something or someone and light means agent that stimulates sight and make things visible. In photography, backlight is a kind of light which comes from or is placed at the back side of the object.

\section{3) Eye Level}

You can shoot at eye level with your subject. (Photographing Shorebirds, July $2,2018)$

Eye level is classified into compounding. Morphologically, it consists of two free morphemes (eye and level). This terminology is constructed by two elements. They are eye and level. The word eye stands as a modifier and level stands as the head. Eye is a noun and level is a noun. This construction is noun compounding because the head of the elements is a noun.

Eye level is a formed word that has a meaning. The meaning is also constructed by its elements. Eye means each of globular organs of sight in the head of human and animals and level means a position on a scale of amount, quantity, extent, or quality. In photography terminology, eye level means the position of lens of camera that is in line with the eyes of the object or as high as the object while capturing. 
Types of Compound

\begin{tabular}{|c|c|c|c|c|}
\hline No & Formation & Sum & $\begin{array}{l}\text { Types of } \\
\text { Compound }\end{array}$ & Examples \\
\hline 1 & Adjective + Adjective & 4 & Adjective & $\begin{array}{l}\text { Super Close, Super } \\
\text { Wide, Pure Black, } \\
\text { Pure White }\end{array}$ \\
\hline 2 & Adjective + Adjective + Noun & 2 & Noun & $\begin{array}{l}\text { Hyper Focal Point, } \\
\text { Hyper Focal Distance }\end{array}$ \\
\hline 3 & $\begin{array}{l}\text { Adjective }+ \text { Conjunction }+ \\
\text { Adjective }\end{array}$ & 1 & Adjective & Black and White \\
\hline 4 & Adjective + Noun & 52 & Noun & $\begin{array}{l}\text { Ambient Light, } \\
\text { Backlight, } \\
\text { Continuous Focus }\end{array}$ \\
\hline 5 & Adjective + Noun + Noun & 17 & Noun & $\begin{array}{l}\text { Full-Frame Image, } \\
\text { Late Day Light, Wide } \\
\text { Angle Zoom }\end{array}$ \\
\hline 6 & Adjective + Verb & 1 & Verb & Override \\
\hline 7 & $\begin{array}{l}\text { Neo-Classical Compound From } \\
\text { Greek }\end{array}$ & 7 & $\begin{array}{l}\text { Neo- } \\
\text { Classical } \\
\text { Compound }\end{array}$ & $\begin{array}{l}\text { Histogram, Tripod, } \\
\text { Perimeter }\end{array}$ \\
\hline 8 & Noun + Adjective + Noun & 1 & Noun & $\begin{array}{l}\text { Multi-Point } \\
\text { autofocus }\end{array}$ \\
\hline 9 & $\begin{array}{l}\text { Noun }+ \text { Adjective }+ \text { Noun }+ \\
\text { Noun }\end{array}$ & 1 & Noun & $\begin{array}{l}\text { Default Close Focus } \\
\text { Distance }\end{array}$ \\
\hline 10 & Noun + Noun & 71 & Noun & $\begin{array}{l}\text { Action Photography, } \\
\text { Ballhead, Camera } \\
\text { Angle }\end{array}$ \\
\hline 11 & Noun + Noun + Noun & 4 & Noun & $\begin{array}{l}\text { DayLight Image, } \\
\text { Exposure Delay } \\
\text { Mode }\end{array}$ \\
\hline 12 & Preposition + Noun & 2 & Noun & Out of Focus, Outline \\
\hline 13 & Preposition + Verb & 1 & Verb & Underexpose \\
\hline 14 & Verb + Noun & 2 & Noun & $\begin{array}{l}\text { Shooting Position, } \\
\text { Shooting Low }\end{array}$ \\
\hline \multicolumn{2}{|r|}{ Total } & 166 & & \\
\hline
\end{tabular}

Table 2 Distribution of Compound

\begin{tabular}{|c|l|c|c|}
\hline No & Types of Compound & $\begin{array}{c}\text { Sum of } \\
\text { Data }\end{array}$ & Percentage \\
\hline 1 & Noun & 155 & $93.4 \%$ \\
\hline 2 & Verb & 1 & $0.6 \%$ \\
\hline 3 & Adjective & 4 & $2.4 \%$ \\
\hline 4 & Phrasal Word & 0 & $0 \%$ \\
\hline 5 & Neo Classical & 6 & $3.6 \%$ \\
\hline & Total & 166 & $100 \%$ \\
\hline
\end{tabular}




\section{d. Clipping}

Creation by shortening or clipping is a word formation process by deleting or omitting one or some syllables in polysyllabic words to make it shorter. In this research, there are three data classified into creation by shortening or clipping. They are photo, pic, and sync.

\section{1) Photo}

Photo is classified into creation by shortening because there is syllable which is deleted or omitted. Morphologically, photo represents the whole or complete single free morpheme as a word although it is clipped. Photo is a noun which is a shortened form of photograph. The syllable graph is deleted to make it shorter. The meaning of photo remains the same as photograph. The meaning is a picture made using a camera whether printed or in digital form.

\section{2) Pic}

Pic is classified into creation by shortening or clipping. Pic is a noun as a shortened form of picture. The syllable ture is omitted or deleted to make it shorter. Morphologically, Pic represents the whole or complete single free morpheme as a word although it is clipped. However, the meaning of pic and picture is still the same. The meaning of picture is a painting or drawing. In relation to photography, picture means an image or photograph made using a camera.

\section{3) Sync}

Sync is a shortened form of Synchronization and it is a noun. Thus, it is classified into creation by shortening or clipping because there are syllables which are omitted or deleted. Morphologically, sync represents the whole or complete single free morpheme as a word although it is clipped. Synchronization or clipped into sync is the operation or activity of two or more things at the same time. For example: the sync between the flash and the shutter.

\section{e. Derivation}

1) Derivation by affixation

Derivation by affixation is a kind of word formation by giving affixes into its base to produce a new word.

a) Brightness

The image preview your camera displays is great for checking composition, but the brightness of the image varies. (How to Use Histograms, May 15, 2018)

Morphologically, the term brightness has two morphemes. The morphemes are bright as a free morpheme and \{-ness\} as a bound morpheme. Bright is an adjective as the base. Then, it gets $\{-$ ness $\}$ as suffix that changes the lexical function. Affixes like $\{$-ness $\},\{$-tion $\},\{-$ age $\},\{$-ency $\},\{$-ence $\},\{$-ity $\}$, etc function as the agent of nominalization in which the word changes its function into a noun (Bauer, 2002).

The word bright stands as an adjective. Bright means the giving out or reflecting light. Then, it gets affixes $\{$-ness $\}$ that changes the class of word from adjective to noun. Brightness means the quality or state of giving out or reflecting light.

b) Reflection

By definition, a reflection creates a mirror image which results in a 50/50 split of the subject matter. (The Highs and Lows of a Horizon, July 9, 2018)

Morphologically, the term reflection has two morphemes. They are reflect as a free morpheme and \{-ion\} as a bound morpheme. Reflect is a verb as the base. Then, it gets $\{-$ ion $\}$ as suffix that changes the lexical function. Affixes like $\{$-ness $\},\{$-tion\}, $\{$-age $\},\{$-ency $\},\{-$ ence $\},\{$-ity $\}$, etc function as the agent of nominalization in which the word changes its function into a noun (Bauer, 2002).

The word reflect stands as a verb. Reflect means throw back without absorbing it. Then, it gets affixes $\{$-ion $\}$ that changes the class of word from verb to noun. reflection means a thing resulted from the reflected light. In 
photography, reflection is an image displayed like seen in a mirror or shiny surface.

c) Photographer I love wildlife photography because there are so many factors that challenge the photographer to create a great image. (Create Captivating Creature Captures, February 12, 2018)

Morphologically, photographer consists of two morphemes. They are photograph as free morpheme and $\{-\mathrm{er}\}$ as bound morpheme. The term photographer is resulted from the word photograph that gets suffix $\{-$ er\}. Affixes like $\{$-ness $\},\{$-tion $\},\{$-age $\},\{-$ ency\}, $\{$-ence $\},\{$-ity\}, etc function as the agent of nominalization in which the word changes its function into a noun (Bauer, 2002). Suffix $\{-\mathrm{er}\}$ functions as the agent of nominalization and the agent or the doer of the action. The word photograph stands as a verb which means an action of taking picture. Then, it gets suffix $\{-$ er $\}$ that changes the function from a verb into a noun indicating the agent or the doer. Photographer means the one who does the activity of taking picture.

\section{2) Conversion}

Derivation without affixation (conversion) is creating already existing lexical word to be another without making a change to its form which is the form of word remaining the same. However, it represents different lexical item. In this research, there is only one datum categorized as derivation without affixation (conversion), to photograph.

Don't squish your subjects together and work in areas with clean backgrounds are just some factors that need to be addressed to get a great wildlife photograph. (Wildlife Family Portraits, April 30, 2018)
Spring is a good time to photograph young if you want to capture newborns. (Wildlife Family Portraits, April 30, 2018)

Morphologically, photograph in sentence 1 and photograph in sentence 2 are similar consisting of one free morpheme. The word photograph in sentence 1 functions as a noun. On the other hand, photograph in sentence 2 stands as a verb. It shows that there is a change of the class of word from noun into verb. It means that there is a conversion of the same word.

\section{f. Eponym}

Eponym is a creation of word based on someone's name. Eponym is very rare to be used in word formation and it is not fruitful. There is only one datum categorized as eponym, silhouette.

When I combine the sky photo with the silhouette or landscape, it becomes my "meal." (Mess with Mother Nature, May 7, 2018)

Silhouette is an eponym. Morphologically, it consists of one free morpheme. It is taken from the name of finance minister of French. He is Etienne De Silhouette who was forced to make a policy to make things cheaper after the economic crisis due to seven-year war. Then, he became popular and the profiles of silhouette were cut from black card, the cheapest way to record a person's appearance.

\section{The Dominant Type}

There are only six out of ten types of word formation found on articles of outdoorphotographer.com published on January to August 2018 namely, acronyms, borrowing, clipping, compounding, derivation and eponyms. 
Table 3 Data Percentage

\begin{tabular}{|c|c|c|c|}
\hline No & $\begin{array}{c}\text { Types of Word } \\
\text { Formation }\end{array}$ & Number of Data & Percentage \\
\hline 1 & Acronym & 12 & $6.06 \%$ \\
\hline 2 & Borrowing & 3 & $1.52 \%$ \\
\hline 3 & Clipping & 3 & $1.52 \%$ \\
\hline 4 & Compounding & 166 & $83.84 \%$ \\
\hline 5 & Derivation & 13 & $6.57 \%$ \\
\hline 6 & Eponym & 1 & $0.51 \%$ \\
\hline \multicolumn{2}{|r|}{ Total } & 198 & $100.00 \%$ \\
\hline
\end{tabular}

Table 3 shows the percentage of types of word formation on photography terminologies. It can be seen that compounding type is the most dominant type of word formation. Compounding consists of 166 data out of 198 total data. Compounding is very dominant covering $83.84 \%$ data. The second position is derivation covering $6.57 \%$ (13 data). The third is acronym consisting of 12 data or $6.06 \%$. On the other hand, Borrowing and clipping have similar number of data. They have $1.52 \%$ or 3 data of word formation. Lastly, eponym only has 1 datum $(0.51 \%)$. In conclusion, compounding is the most dominant type of word formation on photography terminologies consisting $83.84 \%$ data or 166 out of 198 total data.

\section{The Reason of Being Dominant}

There are two reasons of compounding being the dominant type of word formation. The first is due to its simplicity and the second is its specific instruction since photography terminologies deal with instruction on how to operate a camera.

Compounding is very productive in word formation due to its simplicity. Omachnu and Abraham (2012) state that the main motive of using compounding in word formation is because of the need to express concept in new word representing the concept or idea of its element. That is, why compounding is easier to use than the other types of word formation. Compounding is easier so that it is dominant. People can easily combine two or more words to represent a concept or idea and the other people somehow may predict the meaning from the elements constructing the new word.

Compounding is mostly used because it can specify the instruction or it can make instruction to operate the camera clearer. Thus, the instruction can be understood by the photographer easily.

\section{Conclusion}

This research reveals six types of word formation of photography terminologies namely acronym, borrowing, compounding, creation by shortening (clipping), derivation and eponym. Compounding is very dominant covering $83.84 \%$ or 166 out of 198 data. The second position is derivation covering $6.57 \%$ (13 data). The third is acronym consisting 12 data or $6.06 \%$. On the other hand, Borrowing and clipping have similar number of data. They have $1.52 \%$ or 3 data of word formation. Lastly, eponym only has 1 datum $(0.51 \%)$. Compounding is the most dominant word formation type of photography terminologies consisting $83.84 \%$ data or 166 out of 198 total data.

Compounding is the most dominant word formation type of photography terminologies due to its simplicity and its specific instruction. People can express new concept or idea by combining already existing word without any change. It is recommended that readers are encouraged to read more articles to be more familiar with new terminologies on certain domain and writers of published 
articles should consider the provision of more clues on terminologies for the articles.

\section{References}

Aronoff, Mark \& Fudeman, Kristen. (2011). What is Morphology? Second Edition. West Sussex: Wiley-Blackwell.

Bauer, Laurie. (1983). English WordFormation. Cambridge: Cambridge University Press.

Cresswell, John W. (2007). Qualitative Inquiry \& Reseach Design Choosing Among Five Approaches. 2 ${ }^{\text {nd }}$. California: Thousand Oaks.

Giyatmi, Endang Dwi Hastuti, Ratih Wijayava, Sihindun Arumi. (2004). "The Analysis of English Word Formations Used on Brand Names Found in Indonesian Product". Register Journal 7, 179-204.

Katamba, Francis. (1994). English Words. London: Routledge.

Katamba, Francis. (2006). Morphology Second Edition. Hampshire \& New York: Palgrave Macmillan.

Kofoed, Jette and Larsen M.C. (2016). A snap of Intimacy: Photo-Sharing Practices among Young People on Social Media. First Monday Journal Vol. 21. ISSN 13960466.

Lieber, Rochelle. (2009). Introducing Morphology. New York: Cambridge University Press.

O'Grady, William \& Guzman, Videa de. (2001). Contemporary Linguistics: An Introduction $3^{\text {rd }}$ Edition. New York: Pearson.

Omachonu, Gideon S. \& Abraham, David A. (2012). Compounding in Igala: Defining Criteria, Forms and Functions. Unizik Journal of Arts and Humanities, 13. ISSN 1595-1413.
Ring John. (2018). The Grammatical Hierarchy: Words, Phrases, Clauses, and Sentences. Retrieved from https://www.ucl.ac.uk/internetgrammar/clauses/ hierarc2.html. Par.1. Accessed on September 15, 2018.

Siti Zubaidah binti Mustafa, Mageswari Kandasami and Mohamad Subakir Mohd Yasin. (2015). "An Analysis of Word Formation Process in Everyday Communication on Facebook". International Journal of Education and Research 3, 261-274.

Soeprapto Soedjono. (2007). Pot-Pourri Fotografi. Jakarta: Universitas Trisakti.

Stockwell, Roberts \& Minkova, Donka. (2001). English Words: History and Culture. Cambridge: Cambridge University Press.

Sutrisno Widyatmoko. (2009). Irama Visual: Dari Tukang Reklame sampai Komunikator Visual. Yogyakarta: Jalasutra. 